\title{
EDITORIAL
}

\section{Da difusão da produção científica: algumas considerações}

\author{
Antonio Vicente Marafioti Garnica* \\ ORCID iD 0000-0003-0750-8483 \\ Marcus Vinicius Maltempi ${ }^{* *}$ \\ ORCID iD 0000-0001-5201-0348
}

A literatura especializada já apontou e discutiu suficientemente o processo de transformação da Educação em commodity, sob diversos prismas e sob diferentes aportes teóricos. O que se vem notando, portanto, nas mais diferentes faces do sistema educacional, nos vários níveis e modalidades de ensino, já não é um fenômeno novo. O descaso com as instituições de ensino; o desmonte gradativo da educação pública gratuita; a ausência de diálogo para a criação de diretrizes que afetam diretamente crianças, famílias, professores, pesquisadores e gestores; a imobilidade - e a decorrente corresponsabilidade e, em alguns casos, a conivência - das parcelas diretamente afetadas por esse estado de coisas são, dentre outras tantas, manifestações inequívocas do que até pouco tempo só nos era apontado como teoria. As revistas científicas são mais um mecanismo nesse processo contínuo e claro.

No panorama internacional já são raros os periódicos mantidos por instituições de ensino e pesquisa que os produzem com financiamentos estatais que, por sua vez, por sua própria natureza, têm a função de manter e apoiar o avanço da tecnologia e da ciência. Extinguindo-se esses apoios oficiais, resta às revistas científicas exigir dos seus autores a

\footnotetext{
* Editor do BOLEMA. Doutor em Educação Matemática pela Universidade Estadual Paulista "Júlio de Mesquita Filho" (UNESP), Rio Claro, São Paulo. Docente do Departamento de Matemática da UNESP, Bauru, São Paulo, Brasil e dos Programas de Pós-graduação em Educação Matemática UNESP, Rio Claro, São Paulo, Brasil e Educação para a Ciência UNESP, Bauru, São Paulo, Brasil. Endereço para correspondência: Avenida Nações Unidas, 11-35/1101, Bauru, São Paulo, Brasil, CEP: 17010-130. E-mail: vgarnica@ @fc.unesp.br.

${ }^{* *}$ Livre Docente em Educação Matemática pela Universidade Estadual Paulista (UNESP), Rio Claro, São Paulo. Professor do Programa de Pós-Graduação em Educação Matemática e do Departamento de Estatística, Matemática Aplicada e Computação da Universidade Estadual Paulista (UNESP), Rio Claro, São Paulo, Brasil. Endereço para correspondência: Avenida 24A, 1515, Bela Vista, Rio Claro, São Paulo, Brasil, CEP: 13506-900. E-mail: marcus.maltempi@unesp.br.
} 
contrapartida financeira que as permite continuar operando. Na esteira dessas publicações pressionadas pela ausência de apoio adequado, mas que ainda preservam a qualidade dos ensaios e artigos que distribuem - surgem as mais variadas estratégias editoriais às quais recorre uma comunidade ávida pela produção desenfreada que lhe é exigida das instituições. Assim, pesquisadores são diariamente visados por revistas estrangeiras sem qualquer lastro acadêmico e sem a mínima garantia de qualidade que superlotam nossas caixas postais com propagandas sobre as facilidades de publicação que, sem critério, muitas das instituições aceitam e até mesmo promovem. Subjugados pelas pressões da produção e da internacionalização - termos hoje tão comuns nos discursos de gestores e agências de fomento - pouco falta para não sabermos mais distinguir entre joio e trigo. Revistas passam a ser um negócio bastante lucrativo para as poucas editoras que monopolizam o mercado internacional, que se põem a ditar regras independentes de contexto e a oferecer serviços que geram cada vez mais demandas e custos a editores e autores. Com comissões editoriais artificializadas, revistas são criadas sob medida para atender às demandas de uma comunidade que perigosamente e cada vez mais se afasta do bom senso, e eventos internacionais são organizados sob as expensas dos próprios conferencistas e de suas instituições de ensino e pesquisa com a única intenção de promover os próprios conferencistas e suas produções.

O Brasil não se afasta desse movimento, embora aparentemente aqui esse processo seja mais lento, ainda que contínuo e severo. A Coleção SciELO, que tem servido para qualificar os periódicos e que, sob vários aspectos, tem desempenhado bem suas funções, acaba servindo de parâmetro não só para a qualidade, mas também para a concessão dos recursos que permitem o funcionamento dos periódicos. Se essa situação tem sido bem aproveitada pelas revistas inscritas na Coleção, é preciso perguntar-se como fazem para continuar operando aquelas que dela não participam. No caso da Educação Matemática, por exemplo, o BOLEMA é a única revista brasileira pertencente à Coleção SciELO, o que faz com que sua procura pelos autores seja imensa e, por sua vez, implique a necessidade de uma infraestrutura técnica e acadêmica cada vez mais sofisticada e composta de cada vez mais engrenagens e normatizações. Entretanto, por pertencer à Coleção, o BOLEMA é o único periódico que atualmente participa dos Editais de Apoio à Editoração, do CNPq. Mas nossa comunidade de pesquisadores em Educação Matemática é carente de veículos especializados para a divulgação de sua produção. Os poucos periódicos de que dispomos vivem com as dificuldades próprias das revistas que, por não estarem vinculados à Coleção SciELO, sequer podem submeter solicitações de financiamento aos editais abertos pelas agências de fomento e avaliação. Com isso, operam de forma menos ágil, forçosamente não cumprindo aquelas normas exigidas para inscrição na 
Coleção, do que se mantém o já conhecido círculo vicioso: afastadas da Coleção, sofrem pela carência de recursos que, por sua vez, as afasta cada vez mais da Coleção.

Deve-se considerar também, nesse panorama, que a participação na Coleção não é uma empreitada barata: as exigências cada vez mais sofisticadas do SciELO - seja relativa às imposições no formato de apresentação dos manuscritos, seja no que diz respeito ao sistema no qual transitam esses manuscritos para disponibilização na plataforma da Coleção - são onerosas, e muitas vezes, para serem adequadamente atendidas, implicam a contratação de agências especializadas, muitas delas surgidas exclusivamente para atender a essa demanda, movimentando um mercado novo - aquele voltado aos periódicos que participam da Coleção. Também não se deve esquecer das imposições feitas aos editores: a própria Coleção, os indexadores e as agências de financiamento e avaliação parecem se esquecer de que, pelo menos no Brasil, os editores das revistas científicas - ao contrário do que ocorre em muitas instituições estrangeiras - não são profissionais que atuam apenas como editores: eles são professores de cursos de graduação e pós-graduação e, como tal, devem preocupar-se também com aulas, avaliações, relatórios, orientações, eventos, gestão etc. além de exercer sua função como editores. Curiosamente, visando mais a atender a esse mercado e menos voltadas às necessidades e limitações dos editores, as próprias instituições que mantêm as revistas reforçam as exigências, em vez de questioná-las tendo como base suas próprias (im)possibilidades.

As agências de financiamento e avaliação, por sua vez, não têm considerado devidamente esse panorama caótico no qual são produzidas e circulam as revistas científicas. Nos últimos anos, o sistema Qualis-CAPES, talvez visando à criação de uma demanda qualificada com uma aderência mais clara em relação a algumas áreas, foi flexibilizado de forma radical e um tanto artificializada, sem que a essa flexibilização tenha acompanhado a divulgação pública dos argumentos que permitem a periódicos de características e históricos muito distintos se situarem num mesmo estrato. Além disso, deve-se apontar a ineficácia - a inexistência, na verdade - de políticas da CAPES quanto à criação de novos periódicos, num panorama em que, por exemplo, foram instituídos inúmeros Programas de Mestrado Profissional cuja produção, necessariamente distinta daquela dos Programas Acadêmicos, não é divulgada, via de regra, nos periódicos tradicionais. Criar bancos de dados públicos, de livre acesso, com os produtos educacionais gerados pelos Mestrados Profissionais não é ação suficiente por vários motivos. Um deles - talvez o mais óbvio - seja o fato de que os docentes desses Mestrados Profissionais estão sujeitos às mesmas cobranças institucionais dos pesquisadores vinculados a Programas Acadêmicos, mas têm, usualmente, seus trabalhos reprovados nas revistas científicas dada a natureza distinta dessas produções em relação àquelas 
que historicamente esses periódicos divulgam. Essa situação agrava-se ainda mais quando consideramos que o sistema Qualis-CAPES, originalmente criado para avaliação de Programas de Pós-Graduação, tem sido usado por todas as agências de apoio à pesquisa brasileira como padrão para a avaliação de revistas e, por extensão, de_pesquisadores. Ainda que essas avaliações tenham elementos em comum, tomar uma pela outra é uma distorção já naturalizada em nosso meio acadêmico.

Além desses estranguladores todos com que se debatem cotidianamente editores de periódicos científicos, deve-se fazer menção a um outro complicador para que esse quadro seja minimamente representativo: trata-se da questão ética.

O aumento dos casos de plágio é também uma manifestação danosa dessa política de produtividade exacerbada, exigida dos pesquisadores. Se até pouco tempo plágio era um tema que apenas esporadicamente frequentava nossas discussões, atualmente não há um colegiado de instituição de ensino superior sequer que não tenha se deparado com um desses casos lamentáveis. Antes tratado como exceção vergonhosa, hoje o plágio está em vias de banalização, e não se estranha que muitas instituições até promovam e sugiram estratégias artificiais cujo objetivo é o aumento acelerado na quantidade da produção científica dos seus pesquisadores e estudantes de pós-graduação, com diversos outros desdobramentos negativos, conforme Kuhlmann Jr. (2015). Como resultado disso, passaram a ser usuais os detectores de plágio e autoplágio, que tornam ainda mais complicada a dinâmica de gerenciamento das revistas.

Atua como outro complicador decisivo da produção científica, no que diz respeito à questão ética, as imposições da Plataforma Brasil, algumas delas absurdamente ridículas, aplicadas muitas vezes sem qualquer reflexão das Comissões de Ética que as exigem. Não se pode esquecer que, ponto nodal dessas discussões sobre Ética em pesquisa - que infelizmente quase não têm espaço nos Programas de Pós-Graduação, esses nossos centros formadores de pesquisadores -, é o anacronismo de mantermos regulamentações ditadas por algumas áreas e impostas a todas as demais áreas do conhecimento: nossa Comissão Nacional de Ética em Pesquisa (CONEP) é uma comissão do Conselho Nacional de Saúde (CNS). Esforços para reverter esse quadro de distorção têm sido feitos no sentido de incluir nas regulamentações, pelo menos, itens específicos que atendam mais adequadamente, por exemplo, a pesquisa em Ciências Humanas, como os incisos constantes no artigo $1^{\circ}$ da Resolução 510/2016 do CNS (BRASIL, 2016). Esses esforços, entretanto, têm sido insuficientes e esbarram na truculência desnecessária, mas reveladora, das lideranças do CNS. 
Este editorial, em síntese, foi pensado como uma tentativa de contribuir tanto para a defesa da flexibilização das exigências nos editais de financiamento a revistas - para que novos periódicos possam ser criados e os já atuantes possam desenvolver-se ainda mais, de modo a atender convenientemente nossa comunidade -, quanto para incorporar uma voz ao discurso sobre a necessidade de repensar as normatizações relativas à Ética em pesquisa no Brasil; denunciando alguns estrangulamentos que nós, editores, e toda nossa comunidade, sofremos, sem desconsiderar, é certo, o momento caótico pelo qual passamos.

\section{Referências}

BRASIL. Dispõe sobre as normas aplicáveis a pesquisas em Ciências Humanas e Sociais. Resolução n. 510, de 07 abr 2016. Disponível em: <http://conselho.saude.gov.br/resolucoes /2016/reso510.pdf>. Acesso em: 26 set. 2018.

KUHLMANN JR., M. Produtivismo acadêmico, publicação em periódicos e qualidade das pesquisas. Caderno de Pesquisa, v. 45, n. 158, p. 838-855, 2015. Disponível em: <http://ww w.scielo.br/pdf/cp/v45n158/1980-5314-cp-45-158-00838.pdf>. Acesso em: 26 set. 2018. 